\title{
Maternal near miss review: a brief appraisal
}

Sheeba Marwah*, Manjula Sharma

Department of Obstetrics and Gynecology, VMMC and Safdarjung Hospital, New Delhi, India

Received: 03 March 2017

Accepted: 01 April 2017

\section{*Correspondence:}

Dr. Sheeba Marwah,

E-mail: sheebamarwah@yahoo.co.in

Copyright: $\odot$ the author(s), publisher and licensee Medip Academy. This is an open-access article distributed under the terms of the Creative Commons Attribution Non-Commercial License, which permits unrestricted non-commercial use, distribution, and reproduction in any medium, provided the original work is properly cited.

\begin{abstract}
Recuperation of maternal health is mandatory for realms signatory to millennium declaration, as MDG 5A aims at reduction in maternal mortality ratio by three quarters between 1990 and 2015. MM is frequently described as "Just the Tip of The Iceberg" with a vast base of maternal morbidity that still remains largely undescribed. Hence, the concept of maternal near miss (MNM) or severe acute maternal Morbidity (SAMM) was instituted in maternal health care to complement information acquired from MDR. Here we present a succinct review to enlighten and update the readers about the concept of maternal near miss and its advantage in providing the modern-day obstetricians and the administrators an edge over maternal mortality in gauging the quality of health care delivered at each facility. This would thus be instrumental in helping them formulating policies to enhance the health care services at each level across the nation.
\end{abstract}

Keywords: Maternal near miss review, Maternal death review, Maternal health

\section{INTRODUCTION}

Maternal health is an integral part of a country's health care system and fifth Millennium Development Goal. ${ }^{1,2}$ It reflects status of obstetric health and helps in reviewing achievements of facility/country. Besides assisting in conceiving and setting up new goals, it abets in comparison between different countries and sundry regions within a country.

Around 20 percent of all maternal deaths occur in India. ${ }^{1}$ The maternal mortality ratio (MMR) in India is 212 with figures up to 390 in some states. ${ }^{2}$ A mother's death has ruinous upshot on the family unit, and compromises subsistence of the kid atleast upto a decade. ${ }^{3}$ Maternal mortality is believed to be a consequence of the innate risks related with gravidity and parturition, as well as the monetary and sociocultural aspects keeping women away from the available health services. Even after being successful to reach a health infirmary, non-availability of vital facilities and subnormal care may compromise maternal survival. ${ }^{4}$
Conventionally, maternal mortality (MM) has been used as an indicator of maternal health. ${ }^{5}$ It is a sentinel event.5 It is judged by maternal mortality rate (MMR) i.e. no of maternal deaths per 1 lac live births. For this purpose, Maternal Death review (MDR) was launched by MOHFW in India in 2010. ${ }^{6}$ However, now it is not considered sufficient for evaluation of obstetric health in isolation.

\section{WHY MM IS NOT SUFFICIENT?}

Maternal mortality is "just the tip of iceberg" with a vast base to the iceberg-maternal morbidity-which remains undescribed, relatively unevaluated. ${ }^{7}$ Also MMR has declined globally, more so in developed countries. Even in LMIC, absolute number of maternal deaths in facility is low, so it does not allow reliable quantitative analysis of maternal health. In India, MMR has fallen from 212 to 178 per 1 lac live births (SRS 2010-12). ${ }^{8}$ For every woman that dies, many survive a pregnancy complication. Estimated 2, 89000 women died in 2013. ${ }^{8}$ In contrast, 300 million survived and suffered a long 
term/short term disability due to pregnancy and childbirth. ${ }^{8}$ It is therefore quite obvious that for adequate evaluation of maternal health, all these survivors should also be included in analyses.

\section{CONCEPT OF MATERNAL NEAR MISS (MNM)}

Women who experienced and survived a severe life threatening condition during pregnancy, child birth / postpartum are considered as near miss or Severe Acute Maternal Morbidity (SAMM) cases. ${ }^{9}$ Near miss/SAMM cases share many characteristics with maternal deaths and can directly inform about obstacles that have to be overcome after the onset of an acute complication. ${ }^{10}$ Corrective actions for identified problems can then be taken to reduce related mortality and long-term morbidity. Thus, MNM has emerged as an adjunct and proxy measure to identify gaps in maternal health services and act as complementary to maternal mortality

\section{DEFINITION OF MNM}

WHO defines it as "a woman who nearly died but survived a complication that occurred during pregnancy, childbirth or within 42 days of termination of pregnancy". ${ }^{1}$ In practical terms, women are considered near miss cases when they survive life-threatening conditions (i.e. organ dysfunction). MOHFW defines a MNM case as a woman who survives life threatening conditions during pregnancy, abortion, and childbirth or within 42 days of pregnancy termination, irrespective of receiving emergency medical/surgical interventions. ${ }^{6}$

\section{Criteria for identification of MNM case}

\section{WHO recommended three approaches}

- Disease specific criteria e.g. severe preeclampsia/eclampsia, severe hemorrhage/severe sepsis/uterine rupture. ${ }^{1}$

- Management/Intervention based e.g. admission to ICU, procedures like obstetric hysterectomy/massive blood transfusion/intubation/ventilation.

- Organ dysfunction based criteria -based on apparent clinical diseases, clinical markers and management needs. The aim is towards correction of that organ dysfunction to arrest MNM progression to MD. For example, CVS /respiratory/renal/coagulation dysfunction / hepatic /neurological/uterine dysfunction. This is considered as "the most promising frame" for establishing a standard set of criteria. It needs a minimum level of care/basic critical care monitoring facilities-cannot be used in low resource settings.

\section{Indian recommendations for diagnosing $M N M$}

A recent Pilot Study (2014) was conducted by MOHFW over six medical colleges of India developed new comprehensive criteria for use in Indian setup. ${ }^{11}$

\section{These criteria were divided into three groups}

- Pregnancy specific medical/obstetric disorders

- Pre-existing Disorders aggravated by pregnancy

- Incidental/accidental disorders.

For identifying case as MNM, minimum of 3 criteria (Minimum 1 from each of following must be met)

- Clinical findings $(\mathrm{s} / \mathrm{s})$

- Investigations

- Interventions

\section{OR}

Any single criteria which signifies Cardio respiratory collapse

\section{PROCESS INDICATORS OF MNM (WHO)}

These were based on concept of criteria based on clinical audit. Its considered a feasible method of auditing quality of maternal health care. It would be useful for assessing deficiencies and lacunae between actual use and optimal use of high priority interventions in prevention and management of severe pregnancy complications. ${ }^{12}$

\section{MNM indicators}

- $\quad$ Severe maternal outcome ratio $(\mathrm{SMOR})=$ number of women with life-threatening conditions (MNM + MD) per 1000 live births (LB). This gives an estimate of the amount of care and resources that would be needed in an area or facility [SMOR= $(\mathrm{MNM}+\mathrm{MD}) / \mathrm{LB}] .{ }^{1,6,12}$

- MNM ratio $(\mathrm{MNMR})=$ number of maternal nearmiss cases per 1000 live births $(\mathrm{MNMR}=$ $\mathrm{MNM}$ /LB). It gives an estimation of the amount of care and resources that would be needed in an area or facility.

- Maternal near-miss mortality ratio (MNM: 1 MD) refers to the ratio between maternal near-miss cases and maternal deaths. Higher ratios indicate better care.

- $\quad$ Mortality index = number of maternal deaths divided by number of women with life-threatening conditions expressed as a percentage $[\mathrm{MI}=\mathrm{MD} /(\mathrm{MNM}+$ MD)]. The higher the index the more women with life-threatening conditions die (low quality of care), whereas the lower the index the fewer women with life-threatening conditions die (better quality of care).

\section{WHAT IS MNM REVIEW?}

Process of MNM Review (MNM-R) involves the following steps:

- Identification of MNM cases 
- $\quad$ Notification to MO/HOD

- Data transmission (institute district state)

- Review (institutional and district level)

- Analysis and feedback for necessary action

\section{ADVANTAGES OF MNM-R}

Near miss cases are more common than maternal deaths. ${ }^{9}$ Hence MNM-R provides adequate information and analysis. Such cases are rare enough not to overload clinicians and data collection personnel within a facility. Due to higher number, MNM provides more statistically reliable quantitative analysis and more comprehensive profile of functioning of health care system. MNM shares same pathway and pathological processes as MM. (Normal pregnancy $\rightarrow$ morbidity $\rightarrow$ severe morbidity $\rightarrow$ near miss $\rightarrow$ death). ${ }^{12}$ Also, the major reasons and causes are same for both, so review of MNM cases is likely to yield valuable information regarding severe morbidity, which, if untreated may lead to MM. MNM-R seems to be less threatening to service providers. In Cases of MDR, health professionals and other stakeholders involved in service delivery are fearful that the blame would fall on their shoulders. ${ }^{13}$ MDR process is considered as a potential threat to expose them to public scrutiny and outrage. Investigating the instances of MNM-R may be less threatening to providers because the woman survived. ${ }^{14}$ In MNM R, fear of blame and punishment is less. So MNM$\mathrm{R}$ health professionals are willing and eager to share their 'success' stories. Hence more valuable information can be obtained and utilized for improvement of obstetric health and reduction of MMR. ${ }^{15}$ It enables us to learn from MNM survivors as women themselves are available for interview about the care they received. They can share their experiences in ICU, psychological devastation and trauma of being separated from newborn and urge for breastfeeding, besides the psychological perspective of other women who have faced severe maternal illness. ${ }^{16}$ MNM-R provides valuable information about social and family problems and lack of awareness of health care facilities. Level of delays can also be identified where they occur.

\section{Significance of MNM $R$ in reducing maternal mortality}

MNM-R is relatively simpler to analyze, easier to resolve. It is complementary to MDR in appraisal of maternal health. When used in conjunction with MDR, it aids in recognizing patterns and trends of maternal morbidity and mortality, and helps in identifying contributory factors of maternal deaths so that actions can be taken at various levels. It assists in evaluation of quality of health care at a facility and to monitor it. ${ }^{12-15}$ It facilitates detection of lacunae in existing system. Also, it helps in setting up a database to capture all locations and facility details to identify where an MNM case comes from; this assists in focusing interventions in a particular location. MNM R also proves beneficial in gauging and analyzing requirement of health care facilities in terms of infrastructure, human resources and interventional facilities, besides comparing the existing health care and optimal health care of a facility. ${ }^{15}$ Furthermore, identification of delays at various levels can be done, which lead to maternal morbidity and mortality. ${ }^{16}$ Moreover, to identify modifiable socio-demographic factors responsible for maternal morbidity and mortality. It assists in international comparisons in imparting optimal health care. ${ }^{17,18}$

Also, GOI is trying to set up a software to link MNM-R with MDR and maternal and child tracking system. ${ }^{18-20}$ All this data will be computerized and analysed. States and districts can then access reports thus enabling data sharing.

\section{CONCLUSION}

MNM-R is an eminent adjunctive strategy to help identify gaps in health service provision. MNM-R and MDR are complementary to each other. The current MDR format is not equipped to gather information on those pregnant women who delivered through complications and just about averted mortality. Hence, investigating MNM cases aids in taking measures for further amendment of service delivery and programs. When used together, they help in recognizing the contributory factors of maternal deaths so that appropriate actions can be adopted at community and health systems level. MNM is a vital tool that can go a long way in reducing maternal mortality.

\section{ACKNOWLEDGEMENTS}

We are grateful to our patients who bravely fight their ailments daily, and the hard-working laborious residents who work day in and out to save the precious lives of mothers and make them near miss averting impending mortality.

\section{Funding: No funding sources \\ Conflict of interest: None declared \\ Ethical approval: Not required}

\section{REFERENCES}

1. Say L, Pattinson RC, Gülmezoglu AM. "WHO systematic review of maternal morbidity and mortality: the prevalence of severe acute maternal morbidity (near miss)," Reproductive Health. 2004;1(1):10-9.

2. United Nations Millennium Declaration. Fifty-fifth Session of the United Nations General Assembly. New York: United Nations; 2000.

3. WHO, UNICEF, UNFPA, the World Bank. Trends in maternal mortality: 1990 to 2010. WHO, UNICEF, UNFPA, and the World Bank Estimates; 2012.

4. Say L, Souza JP, Pattinson RC. Maternal near misstowards a standard tool for monitoring quality of 
maternal health care. Best Practice and Research 2009;23(3):287-96

5. Purandare CN. Maternal near miss review: a way forward. J Obstet Gynaecol India. 2013;63(4):213-5.

6. Souza JP, Cecatti JG, Parpinelli MA, Serruya SJ, Amaral E. Appropriate criteria for identification of near-miss maternal morbidity in tertiary care facilities: A cross sectional study. BMC Pregnancy Childbirth. 2007;7:20.

7. Stones W, Lim W, Al-Azzawi F. An investigation of maternal morbidity with identification of lifethreatening 'near miss' episodes. Health Trends 1991;23(1):13-5.

8. Noor S, Majid S, Ruby N. An audit of obstetrical hysterectomy. J Coll Physicians Surg. 2001;11:6425.

9. Sahel A, De Brouwere V, Lardi M. Obstetric catastrophes barely just avoided: near misses in Moroccan hospitals. Cahiers/Sante. 2001;11(4):22935 .

10. Sivalingam N, Looi K. Clinical experience with management of 'near-miss' cases in obstetrics. Med J Malaysia. 1999;54(4):496-503.

11. Vandecruys HI, Pattinson RC, Macdonald AP. Severe acute maternal morbidity and mortality in the Pretoria Academic Complex: changing patterns over 4 years. Eur J Obstet Gynecol Reprod Biol. 2002;102(1):6-10.

12. Geller S, Rosenberg D, Cox S. Defining a conceptual framework for near-miss maternal morbidity. J Am Med Womens Assoc. 2002;57:135-9.

13. Pattinson RC, Hall MH. Near misses: a useful adjunct to maternal death enquiries. Br Med Bull. 2003;67:231-43.
14. Cochet L, Macdonald AP, Pattinson RC. Severe acute maternal morbidity and maternal death audit: a rapid diagnostic tool for evaluating maternal care. South Afr Med J. 2003;93(9):700-2.

15. Pattinson RC, Vandecruys HI, Macdonald AP, Mantel GD. Why do women die during childbirth; 2001.

16. Mantel GD, Buchmann E, Rees H. Severe acute maternal morbidity: a pilot study of a definition for a near-miss. Br J Obstet Gynaecol. 1998;105:985-90.

17. Filippi V, Ronsmans C, Gohou V, Goufodji S, Lardi M, Sahel A, et al. Maternity wards or emergency obstetric rooms? Incidence of near-miss events in African hospitals. Acta Obstet Gynecol Scand. 2005;84(1):11-6.

18. Roopa PS, Verma S, Rai L, Kumar P, Pai MV, Shetty J. Near miss obstetric events and maternal deaths in a tertiary care hospital: an audit. J Preg. 2013; Article ID 393758.

19. Sangeeta G, Leena W, Taru G, Sushma K, Gupta N, Amrita P. Evaluation of severe maternal outcomes to assess quality of maternal health care at a tertiary center. J Obstet Gynaecol India. 2015;65(1):23-7.

20. Cecatti JG, Souza JP, Oliveira Neto AF. Prevalidation of the WHO organ dysfunction based criteria for identification of maternal near miss. Reprod Health. 2011;2(8):22.

Cite this article as: Marwah S, Sharma M. Maternal near miss review: a brief appraisal. Int J Reprod Contracept Obstet Gynecol 2017;6:1703-6. 